\title{
Strengthening Primary Health-Care Services to Help Prevent and Control Long-Term (Chronic) Non-Communicable Diseases in Low- and Middle-Income Countries
}

This article was published in the following Dove Press journal:

Risk Management and Healthcare Policy

Mainul Haque, (iD) Tariqul Islam, (iD) ${ }^{2}$ Nor Azlina A Rahman, (DD ${ }^{3}$ Judy McKimm, (iD) ${ }^{4}$ Adnan Abdullah, (iD) ${ }^{5}$ Sameer Dhingra (iD) ${ }^{6}$

'Unit of Pharmacology, Faculty of Medicine and Defence Health, Universiti Pertahanan Nasional Malaysia, (National Defence University of Malaysia), Kuala Lumpur 57000, Malaysia; ${ }^{2}$ UChicago Research Bangladesh, Dhaka 1230, Bangladesh; ${ }^{3}$ Department of Physical Rehabilitation Sciences, Kulliyyah of Allied Health Sciences, International Islamic University Malaysia, Kuantan, 25200 , Malaysia; ${ }^{4}$ Swansea University School of Medicine, Swansea University, Swansea, Wales SA2 8PP, UK; ${ }^{5}$ Unit of Occupational Medicine, Faculty of Medicine and Defence Health, Universiti Pertahanan Nasional Malaysia, (National Defence University of Malaysia), Kuala Lumpur 57000 Malaysia; ${ }^{6}$ School of Pharmacy, Faculty of Medical Sciences, The University of the West Indies, St Augustine Campus, Mount Hope, Trinidad \& Tobago

Video Abstract

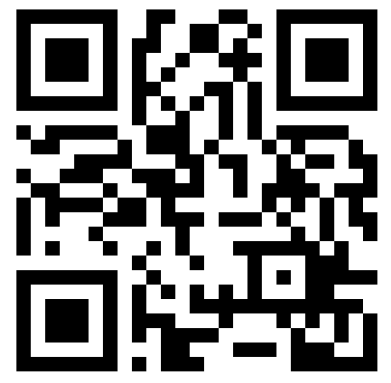

Point your SmartPhone at the code above. If you have a $Q R$ code reader the video abstract will appear. Or use: https://youtu.be/33l6gKIRNFo

Correspondence: Mainul Haque

Faculty of Medicine and Defence Health, Universiti Pertahanan Nasional Malaysia, (National Defence University of Malaysia), Kem Perdana Sungai Besi,

Kuala Lumpur 57000, Malaysia

Tel +60 109265543

Email runurono@gmail.com
Abstract: The prevalence of long-term (chronic) non-communicable diseases (NCDs) is increasing globally due to an ageing global population, urbanization, changes in lifestyles, and inequitable access to healthcare. Although previously more common in high- and uppermiddle-income countries, lower-middle-income countries (LMICs) are more affected, with NCDs in LMICs currently accounting for $85-90 \%$ of premature deaths among 30-69 years old. NCDs have both high morbidity and mortality and high treatment costs, not only for the diseases themselves but also for their complications. Primary health care (PHC) services are a vital component in the prevention and control of long-term NCDs, particularly in LMICs, where the health infrastructure and hospital services may be under strain. Drawing from published studies, this review analyses how PHC services can be utilized and strengthened to help prevent and control long-term NCDs in LMICs. The review finds that a PHC service approach, which deals with health in a comprehensive way, including the promotion, prevention, and control of diseases, can be useful in both high and low resource settings. Further, a PHC based approach also provides opportunities for communities to better access appropriate healthcare, which ensures more significant equity, efficiency, effectiveness, safety, and timeliness, empowers service users, and helps healthcare providers to achieve better health outcomes at lower costs.

Keywords: primary health care, PHC, prevention, control, chronic, long-term conditions, non-communicable diseases, NCDs, lower-middle-income countries, LMICs

\section{Introduction}

Global healthcare is currently struggling with a massive burden of long term (chronic) non-communicable diseases (NCDs) which risks slowing the growth of the human development index, which comprises life expectancy, education, and per capita income. ${ }^{1-3}$ Whilst NCDs are not infectious or transferable directly from one person to another, they are frequently long-term (chronic) conditions, which can last a lifetime in some cases. NCDs result from a combination of "genetic, physiological, environmental" and lifestyle issues. ${ }^{4}$ The major categories of NCDs are cardiovascular diseases (ischemic heart and brain disease), cancers, chronic respiratory diseases [eg, chronic obstructive pulmonary disease (COPD), and bronchial asthma] and Type 2 diabetes. ${ }^{4}$ NCDs were initially seen as a public health $(\mathrm{PH})$ problem for wealthy countries; ${ }^{5}$ however, NCDs are rapidly increasing even among rural 
populations of low- and middle-income countries (LMICs). ${ }^{6}$ Although most NCDs are often preventable, globally, they kill 41 million people per year: $71 \%$ of all deaths. ${ }^{4}$ NCDs are also responsible for many premature deaths, with 15 million people aged 30-69 years dying prematurely; of these, $85-90 \%$ are from LMICs. ${ }^{4,7}$ In High-Income Countries (HICs) and LMICs alike, NCDs contribute to the poor health status of both individuals and communities. NCDs are a significant burden on healthcare systems, increasing healthcare overheads for governments as well as being costly for individuals in terms of out-ofpocket expenses. ${ }^{8-13}$ They also impact the broader economies of countries because people are unwell or dying early, therefore, they are not contributing fully to society economically or socially. Considering the impact of NCDs on health, the World Health Organization (WHO) has developed a global strategy and action plan for the prevention and control of NCDs, ${ }^{14,15}$ aiming for a " $25 \%$ relative reduction in premature mortality" from long-term NCDs by $2025 .{ }^{16}$ This narrative review (NR) paper will primarily focus on the potential and role of PHC services in the prevention and control of NCDs in LMICs.

\section{Primary Health Care: A Brief Introduction}

\section{Primary Health Care Experience in the United Kingdom: A Case Example}

Many countries overhauled their health and social systems as a response to the first World War (WW1) massive loss of life, and the social reconstruction required as countries started to recover. In the UK, a series of health and welfare reforms had begun to be implemented after the Crimean war, which was stimulated further during and after WW1. These reforms were primarily a response to the realization that many of the soldiers recruited were in very poor health, and the liberal government of the day wanted to provide a comprehensive welfare system for its people. In 1919, Lord (Dr.) Bertrand Dawson was appointed by the government to chair a commission for the improvement of the health system. Dawson was a doctor at the London Hospital and was very motivated by the groundbreaking progress in the healthcare of the Soviet Union, where the new healthcare structure utilized local administrative bodies to provide health care services which employed both generalists in local polyclinics, with more specialized care being provided in tertiary hospitals. In 1920 he reported back to the government, suggesting that the
British healthcare system was inadequate, deteriorating in both quality and quantity and that health professionals were failing to upgrade their knowledge and practice as per scientific progress. The health system was, therefore, not delivering an effective healthcare service for the general public. ${ }^{17-20}$ Dawson presented his vision of replacing the existing disorganized and profit-making healthcare system with coordination between primary and secondary healthcare centers, with tertiary/teaching hospitals for a defined geographical area, to ensure the best healthcare for all communities. ${ }^{19,20}$ A central part of this would be "Primary Health Centers." "The distinguishing feature of these Primary Health Centers ... would be that they would be staffed by general practitioners. $" 21$

At the time, this vision was never operationalized because of a lack of political commitment and huge resistance from the medical profession, as doctors' earnings were based on private fees, and they did not want to be in a public salary-based system. The medical profession said that Dawson's plan would increase healthcare costs for individuals and for public systems. ${ }^{19}$ After the Second World War (WW2), the second series of welfare reforms were put in place, which included the formation of the National Health Service (NHS) in 1948, free at the point of use and available to the whole population. This enshrined Dawson's idea for primary health care (PHC), secondary care (provided by local general hospitals), and tertiary care provided in super-specialized centers and teaching hospitals. ${ }^{20-23}$ The PHC system in the UK continues to provide the first point of contact for healthcare for the whole population, with general practitioners (GPs, family doctors) acting as gatekeepers for access to secondary care. ${ }^{24,25}$

\section{The Alma Ata Declaration}

Although many examples of PHC systems were emerging around the world, including the UK example described above, it was not until the mid-1970s that the concept of PHC as a central and vital part of any health system took root globally. The concept of primary health care (PHC) as a strategic direction for international health systems was first tabled to the Executive Board of the WHO in January 1975. It took the form of seven principles that should be implemented by national health systems aiming to develop their health care services. ${ }^{26-28}$ These principles emphasized that PHC should be framed 
Around the life patterns of the population; for their involvement; for maximum reliance on available community resources while remaining within cost limitations; for an integrated approach of preventive, curative and promotional services for both the community and the individual; for interventions to be undertaken at the most peripheral practicable level of the health services by the workers most simply trained for this activity; for other echelons of services to be designed in support of the needs of the peripheral level. ${ }^{27}$

It was expected these PHC principles would be put in place in collaboration with other health promotion elements of local communities and national governments to ensure the best possible healthcare for the global population. $^{29,30}$ An International Conference held in Alma Ata, Kazakhstan in 1978, jointly organized by the WHO and the United Nations Children's Fund (UNICEF), placed the PHC plan as central to the strategy to ensure health for all. ${ }^{31,32}$ Subsequently, 134 countries around the globe endorsed the motion of the Alma Ata Declaration. $^{31,32}$ The Alma Ata declaration was disseminated widely and centralized PHC as an official part of health policy planning strategy for all WHO affiliated nations 31,32 to accomplish "health as a state of complete physical, mental and social well-being, and not merely the absence of disease or infirmity". 33

Currently, $\mathrm{PH}$ and $\mathrm{PHC}$ (the terms are used interchangeably) are the foundation of maintainable and workable health systems and should be enshrined in national and international health policies. ${ }^{34}$ Medical and other health professions' education programs should be provided to develop and implement effective, equitable, efficient, and affordable healthcare programs all over the world. ${ }^{34} \mathrm{~A}$ recent scoping review suggests that defining the primary objectives of a PHC program and the aptitudes and capabilities of the workforce required are a fundamental first stage (particularly for LMICs) in designing and implementing robust and accountable PHC services that are responsive to community health needs. ${ }^{28}$

\section{The Burden of Long-Term (Chronic) NCDs in LMICs}

As mentioned earlier, NCDs are not only a major cause of death but also the cause of many disability-adjusted life years (DALYs). DALYs are a measure of the overall disease burden expressed as the number of years lost due to ill-health, disability, or early death, with one DALY being one lost year of a "healthy" life. DALYs for a disease or health condition are calculated as the sum of Years of Life Lost (LL) due to premature mortality in the population and the Years Lost due to Disability (YLD) for people living with the health condition or its consequences. ${ }^{35}$ Socioeconomic disparities and lack of access to preventive and primary health care services are a key factor in the initial acquisition of and complications from such chronic diseases, particularly in LMICs. ${ }^{36,37}$ Disease surveillance and reporting programs are officially recognized systems that systematically evaluate the health of the population to develop preventive, control, and treatment strategies aimed at reducing morbidity and mortality rates. ${ }^{38,39}$ The collection, preservation, analysis, and interpretation of accurate health-related data involves immense expertise and is highly resource-intensive. Disease surveillance programs in LMICs have been identified as a significant concern because of a lack of health informatics and data management skills. ${ }^{40-42}$ The issue is further confounded in LMICs, as many have both NCDs and infectious diseases (IDs) as major public health issues and consequently there is a substantial double disease burden of both NCDs and IDs such as tuberculosis (TB), HIV/AIDS, malaria, and other parasitic diseases. ${ }^{42}$ Although TB is not strictly an NCD as it is a chronic infectious disease, it has a longterm impact on patients and communities and remains one of the top causes of death around the globe. This is particularly impactful in LMICs, including India, China, Indonesia, the Philippines, Pakistan, Nigeria, Bangladesh, and South Africa. The extent of the twin (NCDs and IDs) public health problem in LMICs has been widely reported. ${ }^{36,43-46}$ For example, the prevalence of both Type 1 and 2 diabetes is increasing all over India, and it has been reported that $5-15 \%, 4-6 \%$, and $2-5 \%$ of Indian urban, semi-urban, and rural populations respectively are suffering from Type 1 diabetes. $^{47,48}$ In 2008, it was reported that China has 92.4 million diabetic patients with a national prevalence of $9.7 \%$ among adults. ${ }^{49}$ Therefore, LMICs need to adopt innovative strategies to reduce mortality and morbidity due to NCDs and IDs. ${ }^{50-54}$

\section{Materials and Methods}

This is a narrative review (NR) and not a systematic review or meta-analysis. It aims to provide a narrative, drawn from relevant literature, around the history and current state of PHC in helping to prevent and control NCDs and reduce their burden on populations' health. The review is based on published literature available to 
the Universiti Pertahanan Nasional Malaysia (UPNM, National Defence University of Malaysia), searches were carried out using EBSCO, PubMed, and Google Scholar. The study was conducted between May-25-2019 to November-12-2019. Search terms were primary health care, prevention, control, long-term conditions, chronic non-communicable diseases, NCDs, LMICs, history, burden, strengths, epidemiology, and prevalence. Pertinent journals identified were also hand-searched, and references were scanned to find additional literature.

\section{Epidemiology of Chronic NCDs in LMICs}

Approximately 40.5 million people per year die from NCDs around the globe, ${ }^{55}$ with around 13 million people between the ages of 30-69 years from LMICs dying prematurely from NCDs. ${ }^{4}$ Currently, 31.5 million (more than $75 \%$ ) of global deaths occur in LMICs and whilst the WHO predicts that the global burden of NCDs will rise to $80 \%$ by $2020,{ }^{55}$ an excessive burden will be placed on LMICs, with $70 \%$ of deaths occurring in these countries, with at least $50 \%$ of these deaths being premature. ${ }^{16,56,57}$ We now highlight three regions as examples of the impact of NCDs on LMICs.

\section{Sub-Saharan African Countries}

One example of the disparity between high and low/middle-income countries is that whilst NCDs will increase in the next decade globally on average by $17 \%$; it is predicted that the burden on African nations might increase by $27 \%{ }^{16}$ In sub-Saharan African countries, the death rate due to NCDs has been continually increasing. ${ }^{7,16,59,60}$ For example, in the small country of Malawi, NCDs related deaths account for $28 \%$ of the total deaths. ${ }^{59}$ Alongside difficulties in gathering and analyzing health-related data, many African countries are also struggling with political and social unrest and environmental related issues, all which lead to a lack of robust data and slow implementation of policies. Therefore, despite a growing trend towards an increase in NCDs associated with morbidity and mortality, there has been a failure across the continent to achieve the WHO recommendations. ${ }^{61}$

\section{India and Other Asian Countries}

Almost $50 \%$ of NCDs related deaths occur in Asian countries, which accounts for $47 \%$ of the global disease burden. ${ }^{16,58}$ As with many other LMICs, India (one of the highest populated countries) does not possess comprehensive data on NCDs and related issues, but they are ever-increasing, typically in the forty-five years' age group. $^{62-64}$ From 1990-2016, India has developed a state-level epidemiological data bank, which was used in the Global Burden of Diseases, Risk Factors, and Injuries (GBD) study in 2017. ${ }^{65,66}$ From this, three papers published in the Lancet Global Health reported that NCDs, especially CVDs, respiratory disorders, and diabetes (both type 1 and 2), are increasing among Indian populations. ${ }^{41,67,68}$ Indian patients with NCDs comprised around $61 \%$ of the overall deaths per year, ${ }^{69}$ with CVDs, chronic respiratory disease, cancer, and diabetes contributing to $45 \%, 22 \%, 12 \%$, and $3 \%$ of all NCD deaths, respectively. ${ }^{70}$ CVD-related disability-adjusted life years (DALYs) lost in the Asia Pacific region accounted for more than $50 \%$ of global DALYs lost due to cardiovascular issues in 2005. ${ }^{71}$ Four NCDs (CVDs, chronic respiratory diseases, cancer, and Type 1 and 2 diabetes) remain the top causes of mortality in South-East Asia, accounting for 8.8 million lives, ie, $64 \%$ of all deaths. ${ }^{72}$

\section{Central America, the Latin, and Non- Latin Caribbean Countries}

Again, data is patchy across these regions, but similar trends, as discussed above, can be seen. Between 2010 and 2013, deaths attributed to NCDs ranged from 454.2 per 100,000 in Central America (the highest rate) to 297.3 deaths per 100,000 in the Non-Latin Caribbean (the lowest rate). ${ }^{73-75}$ In comparison, external causes of death, such as road traffic injuries and suicides, were also highest in Central America at 90.2 per 100,000 compared with the lowest at 38.7 per 100,000 in the Non-Latin Caribbean. ${ }^{73}$ Central American countries, therefore, had the highest mortality rates of communicable diseases, NCDs, and external causes in 2010-2013. ${ }^{73}$ Another study in 1990 reported death rates and DALYs of $69 \%$ and $65 \%$ in Latin American and Caribbean (LAC) nations, respectively. ${ }^{74}$ Similar rates of mortality (73\%) and DALYs (76\%) were observed with CVDs being the major cause of NCDs related mortality, and psychiatric conditions and external injuries being the major reasons for DALYs. ${ }^{74}$ The main reasons for the high rate of NCDs in LAC nations were attributed to increased life expectancy, changes in lifestyle, and rapid urbanization. ${ }^{75,76}$ The US Agency for International Development (USAID) reported that NCDs accounted for around $50 \%$ of all deaths, infectious diseases 
for $30 \%$, and injuries for $20 \%$ in LAC nations. ${ }^{75,76}$ The USAID also similarly reported that CVDs and psychiatric disorders were a principal cause of both deaths and DALYs in LAC countries, with around $31 \%$ of all deaths due to CVDs. $^{77}$ In $2006 \mathrm{~m}$ the WHO estimated that in LAC nations, the NCDs-linked death rate would double, particularly due to ischemic heart disease, stroke, and Type 1 diabetes, with a potential increase in lung, breast, and prostate cancer-associated deaths. ${ }^{78}$

\section{Strengths of Primary Health Care}

As described earlier, in 1978, 134 countries approved the Alma Ata declaration that "health as a foremost human right" and recognized PHC as essential to providing health to all by 2000 . PHC was visualized as

The first level of contact of individuals, the family and community with the national health system, bringing health care as close as possible to where people live and work and constituting the first element of a continuing health care process. ${ }^{79}$

PHC is essential health care based on practical, scientifically sound, and socially acceptable methods and technology made universally accessible to individuals and families ........ the cost that the community and country can afford to maintain at every stage of their development in the spirit of self-reliance and self-determination. ${ }^{55}$

The principles of PHC include: "accessibility, public or community participation, health promotion, appropriate use of technology, and intersectoral collaboration". 56

The Alma Ata vision started to turn into reality as communities around the world began to use PHC for healthcare support, and its impact on curative and preventive health issues began to be measured. ${ }^{80,81}$ For example, by 2004 , the World Bank was reporting that $90 \%$ of health issues were regularly resolved at the level of the PHC, with only $10 \%$ requiring specialist hospitalized medical care. ${ }^{82}$ This had specific impact on marginalized communities around the globe, both rural and urban, who often do not have access to high-quality secondary or tertiary healthcare services ${ }^{83,84}$ and for whom PHC ensures access to healthcare, irrespective of the individual's or communities' financial and social status. ${ }^{85,86}$

In countries (such as those in Europe, Canada, and Australia) where PHC is more longstanding and robust data has been collected over many years, a body of evidence of the positive impact of a PHC based system is amassing. A European study analyzing PHC data from
2009-2010 found that effective PHC programs in Europe improved the overall health status of the ordinary people of the European Union (EU), ensured health-related equity, and reduced hospitalizations. ${ }^{87}$ Another EU study conducted in twenty-nine European countries reported that patients with long term (chronic) conditions enjoyed good or perfect health in those EU countries, which had a useful and well-organized PHC program. ${ }^{88}$ Additionally, patients with multiple co-morbidities obtain considerably more assistance from a robust PHC system. ${ }^{88}$ In Canada, PHC has been categorized into five primary care organizational models, four professional and one community, with professional models (single-provider, contact, coordination, and integrated coordination) serving $90 \%$ of users. ${ }^{89} \mathrm{~A}$ Canadian study found that the coordination-integrated and community models were more useful than PHC models in the management of more advanced long-term NCDs. ${ }^{90}$ Multiple studies report that PHC initiatives are linked with higher quality healthcare. ${ }^{91-93}$ For example, $\mathrm{PHC}$ can reduce the total mortality rate, including premature death, often caused by chronic respiratory, CVDs, cancer, infant mortality, low birth weight, and self-rated health and the improved access to healthcare provided by $\mathrm{PHC}$ is related to a higher level of patient satisfaction and reduced total health spending. ${ }^{91-93}$

Multiple Australian research studies also report that a comprehensive PHC strategy comprises a range of healthcare activities, including promotional, preventive, rehabilitative, and curative, which have a positive impact on population health. $^{94-96}$ A comprehensive PHC strategy was subsequently reported as an effective method to address complex health issues and reduce inequities and was a better healthcare model in terms of ensuring the overall health of the whole population. ${ }^{97-99}$ Finally, we note that the Republic of Cuba had provided free government-run accessible healthcare to over $90 \%$ of the population by 1975 . The country now offers accessible and affordable healthcare for the whole population, and whilst health statistics vary, historically, the country has had good health indices. ${ }^{100,101}$ The country also trains doctors and provides free medical aid to many LMICs and countries experiencing disasters around the world. ${ }^{102}$

One area where high-income countries and NGOs (non-governmental organizations) might lend their knowhow and expertise to LMICs is in the use of technologies, both in management systems as well as for medical use, such as point of care monitoring and diagnostics. The WHO describes Appropriate Healthcare Technology (AHT) as 
methods, procedures, techniques, and equipment that are scientifically valid, adapted to local needs and acceptable to those who use them and to those for whom they are used, and that can be maintained and utilized with resources the community or country can afford. ${ }^{103}$

Appropriate technology is essential for the proper care and prevention of NCDs, and the WHO suggests utilizing "cost-effective, affordable, safe, evidence-based, and proven" 52 technologies for the prevention and monitoring of NCDs, especially in LMICs. ${ }^{52,104-106}$ However, running a successful NCD service in PHC needs skilled human resources, management systems, relevant medicines with an adequate supply, and appropriate equipment. ${ }^{107-109}$ In LMICs, these are often limited due to financial considerations or a weak health infrastructure. ${ }^{110,111}$

In PHC specifically, incorporating technologies into the services provided has the potential to accelerate $\mathrm{PHC}$

as the integrative hub for health care, supporting the efforts of patients, promoting collaboration with specialists, facilitating connections with nursing homes and home health, and advancing population health within a framework that improves the patient experience, quality, and value. $^{112}$

As mobile and communication technologies are further developed and made more affordable, this provides many opportunities to involve patients in managing and monitoring their health. This is particularly relevant to the management of long term NCDs, as patients' self-management of NCDs and comorbidities plays a vital part in reducing complications, reducing hospital admissions, and managing conditions well. ${ }^{112-115}$

Despite challenges, in many LMICs, progress is being made towards implementing PHC systems and services. For example, fourteen LMICs (Costa Rica; Cuba; Brazil; Bolivia; Mexico; Niger; Ghana; The Gambia; Thailand; Sri Lanka; Kerala, India; Iran; Afghanistan and Liberia) have implemented large scale PHC programs and made significant progress in providing public healthcare. ${ }^{28,116}$ Another study found that providing health workers (not graduate medical doctors) ensured better coverage and quality care, but there is a need for enhancing cooperation and integration with the PHC services of LMICs. ${ }^{117}$ This study additionally found community-based healthcare services (CBHCSs) were most effective, observing that CBHCSs perform much better when these clinics are well-organized and integrated with proper referral systems, supervised support, and the medicine supply chain. ${ }^{117}$ This highlights one of the issues for many LMICs in which have deficiencies in their health management and structural infrastructures due to lack of financial and human resources. Once these are addressed, then PHC services work more efficiently as part of a holistic systems-oriented approach to healthcare delivery. ${ }^{118,119}$

\section{PHC Is a Comprehensive Whole-System Approach}

One of the great strengths of a PHC based system is its holistic, whole-systems approach from prevention through to long term health maintenance. From the outset, PHC was conceptualised as

comprehensive in that its related health services to the broader organization of society, calling for a new international economic order that would benefit developing nations, empowering democratic participation in health, and greater attention to social and environmental contexts that increased disease risks. ${ }^{120}$

Intersectoral collaboration and communication is also vital in promoting health, defined by the WHO as

a recognized relationship between part or parts of the health sector with parts of another sector which has been formed to take action on an issue to achieve health outcomes (or intermediate health outcomes) in a way that is more effective, efficient or sustainable than could be achieved by the health sector acting alone. ${ }^{121}$

This reflects the wide definition of "health" taken by the WHO as "a state of complete physical, mental and social well-being and not merely the absence of disease or infirmity", ${ }^{122}$ which was reaffirmed in the Alma Ata Declaration. ${ }^{55}$ In order to achieve this, the involvement of multiple stakeholders from various sectors is a necessity. $^{123}$

Health and healthcare systems are dependent on multiple factors such as "social, political, economic and environmental", ${ }^{124}$ which for NCDs (such as CVD, Type 1 diabetes, chronic respiratory diseases, and cancers) include the environment, living arrangements, the effect of rapid urbanization, and food habits, which provides for access to wholesome and nutritious foods, and educational level. ${ }^{52}$ These factors impact personal health and that of communities, and therefore intersectoral collaboration is needed between public, private, and NGO stakeholders at international, regional, countrywide, provincial/county, and local levels, often co-ordinated most effectively within 
a PHC system. ${ }^{124,125}$ Intersectoral collaboration, especially between the private sector and other health-related stakeholders, has been proven successful in significantly improving the impact of NCDs. ${ }^{126-129}$ In many LMICs, intersectoral cooperation is more challenging because of the more fragile, lower-resourced, and poorly integrated organizational and administrative healthcare system. ${ }^{128}$ However, there have been successes in inter- or multisectoral collaboration in improving health for patients with NCDs' in LMICs. ${ }^{130,131}$

Intersectoral teamwork is an essential component of person-centered healthcare aimed at meeting the Sustainable Development Goals (SDGs). ${ }^{128,132}$ As mentioned above, long term (chronic) NCDs are often associated with the overall quality of life, poverty, urbanization, the consumption of safe and nutritious foods, and educational level. ${ }^{77,133}$ Therefore, NCDsrelated policies and planning activities need to involve all sectors responsible for health and wellbeing. ${ }^{4}$ Placing PHC as a fundamental partner in intersectoral collaboration helps to promote collaborative policies, including town planning, safe and nutritious food production, and widespread participation of the private health sector to address the impact of cardiovascular diseases, diabetes, lung diseases and many cancers. ${ }^{52}$ Meaningful and sincere collaborations between the public and private health sectors and other health-related sectors have proven effective in minimizing the impact of long-term NCDs. ${ }^{134,135}$ For example, in Denmark, intersectoral and private sector collaboration successfully resulted in producing safer food by minimizing saturated fat in factory processed food. ${ }^{136}$ This initiative put an additional tax on foods with high saturated tax, and, across the country, the intake of saturated fat reduced by $4.0 \%$, there was increased intake of vegetables and salt, and mortality caused by NCDs reduced by $0.4 \%{ }^{136}$ Many countries have succeeded in improving health by introducing additional taxes on sugar and sugar-sweetened beverages (SSBs), which has reduced their consumption and, subsequently, the frequency of NCDs, as sugar and SSBs are positively correlated with a high incidence of NCDs. ${ }^{137,138}$ Similar success was obtained by reducing the consumption of tobacco by increasing the tax for tobacco and related products. ${ }^{139,140}$ Multiple studies reported that intersectoral collaboration combined with community engagement among all health care stakeholders of LMICs improves healthcare indices and access to healthcare in these countries. ${ }^{141-143}$

\section{PHC Enhances Community Participation}

Community participation or engagement, another principal strength of PHC, has been reported as being highly influential on the prevention and control of NCDs. ${ }^{144}$ Community participation is described as a method and practice by which ordinary people and societies are empowered to be involved dynamically and meaningfully in identifying and describing the health-issues concerning themselves. ${ }^{69}$ It also includes communities making their own decisions about health issues that impact on their lives, formulating and implementing strategies, organizing, preparing, formulating, developing and delivering healthcare services, and taking action to accomplish significant improvements in healthcare. ${ }^{145,146}$ Multiple systematic reviews find that community participation and empowerment lead to improvements in health and healthcare by implementing policies and plans suitable for the local and national context. ${ }^{147-149}$ NCDs are complex in nature, frequently related to the lifestyle, activities, and socio-cultural norms of the community, ${ }^{150}$ therefore community participation, which requires the "human science of communication and counseling," can help enhance more traditional medical care. ${ }^{151}$

Community engagement has been described as an enabling instrument through which residents of the community take charge of identifying and analyzing their needs to resolve their own healthcare issues and future planning for development. ${ }^{152}$ A recent systematic review reported that community participation is central to developing a rights-based strategy to improve the overall healthcare system, and that community participation has proven its potential to act effectively in improving healthcare by enhancing positive public health perspectives. ${ }^{153}$ This review also reported that, around the world, community participation has long-term positive health consequences and leads to more efficient spending on healthcare. ${ }^{153}$ With specific relevance to LMICS, the active involvement of communities in PHC programs with governmental support led to improved health outcomes and health equity in fourteen LMICs. ${ }^{28,116}$ And in relation to the control of infectious diseases and NCDs around the world, multiple studies report that community participation and engagement play an essential and positive part. ${ }^{52,154-164}$

\section{PHC Emphasis on Promoting Health Equity}

No single precise definition of equity exists, as it is a subjective concept encompassing notions of neutrality, 
morality, equality, impartiality, and righteousness. ${ }^{165}$ The Institute for Healthcare Improvement (IHI) suggests that

ideally everyone should have a fair opportunity to attain their full health potential and, more pragmatically, no one should be disadvantaged from achieving this potential if it can be avoided

This is health equity. ${ }^{166}$ The concept of equity is not new, however, and has its roots in ancient Greek philosophy. Aristotle defined two types of equity in relation to privileges and services: horizontal and vertical equity. ${ }^{167-169}$ Horizontal equity involves providing treatment to everyone equally, aiming to eliminate social and economic inequity (often through equality legislation or policies) based, for example, on race, gender, disability, and other factors. ${ }^{165}$ Vertical equity refers to providing different treatment or care to various individuals or groups because their needs are different, even if they have characteristics in common. ${ }^{170}$ Healthcare strategies and planning, therefore, need to consider how best to address inequities in health access and provision from both perspectives. ${ }^{171,172}$

NCDs affect both poorer and richer communities in all high, middle- and low-income countries, however, they have the most impact on communities marginalized by reduced access to appropriate, timely healthcare, the majority of whom are in LMICs. ${ }^{173}$ Access to healthcare can be limited for various reasons, either because the necessary healthcare facilities do not exist, or facilities are not equipped with essential equipment and trained healthcare staff, or there is poor availability of essential medicines. ${ }^{174,175}$ Health inequity is compounded by poverty and lack of health education. ${ }^{134}$ For example, NCDsrelated morbidity and mortality are often associated with high consumption of tobacco, alcohol, and unhealthy foods. ${ }^{38,176}$

Horizontal equity in healthcare systems is seen as vital to improve the impact of NCDs, ${ }^{52}$ and PHC is central to this. PHC's main aim is to ensure equity of healthcare access to all individuals, irrespective of social status, which includes marginalized communities, more impoverished people in poorer countries, and older people who are disproportionally affected by NCDs. ${ }^{80,174,177,178}$ Another advantage of PHC is that health promotion and preventive care are provided alongside direct clinical care, therefore improving the health status of patients at risk of NCDs as well as those with NCDs, this is particularly impactful in LMICs where public health systems may be inadequate. ${ }^{179-181} \mathrm{PHC}$ is, therefore, central to addressing issues of both horizontal and vertical inequity and health care policies that address these improve the individual, community, and the country's overall earnings and economic growth. ${ }^{182-184}$ This has been confirmed by multiple studies that report that, after the adoption of a PHC program in LMICs, health equity has improved, especially in the management of NCDs. ${ }^{28,87,100,101,116,117,185,186}$

In terms of long-term (chronic) NCDs, improving healthcare equity is vital. NCDs often do not produce any symptoms until the disease process damages the physiological system. For example, hypertension is frequently described as a "silent killer," as often no symptoms emerge until vital organs such as the heart, brain, or kidney are damaged, with an individual typically first presenting with acute myocardial infarction, stroke, or renal failure. ${ }^{187,188}$ Screening programs to identify and monitor individuals at risk help alleviate such serious clinical consequences by preventing disease progression. ${ }^{188}$ Both patients being monitored, and those who have been diagnosed with an $\mathrm{NCD}$, need proactive, patient-centered, individuallyoriented, and maintainable care, which may be for many years, even for the patient's whole lifetime. As the WHO recommends, in most countries, PHC is the most appropriate setting, and service for the provision of the longitudinal, patient-centered care that individuals with NCDs require. ${ }^{188}$ This is supported by studies from many settings in LMICs. Multiple studies report on the success of PHC systems in the management and monitoring of NCDs, including hypertension and diabetes among Palestine refugees and in Malawi. ${ }^{189-195}$ A systematic analysis of the global burden of disease involving 187 countries concluded that PHC had great potential in controlling and prevention of NCDs in LMICs. ${ }^{196}$ Another systematic review into the high volume of NCDs (principally cardiovascular disease, respiratory disease, diabetes, and cancers) in sub-Saharan African (SSA) countries concluded that health policies and strategies that incorporated political determination, health education and promotion amongst the public, and national and international collaborations were imperative to control and manage of NCDs. ${ }^{54}$ Although a PHC system was not overtly discussed, the policy program principles suggested align with the inherent concepts of PHC.

\section{Discussion and Conclusion}

The prevention and control of long-term chronic conditions such as NCDs is a major public health challenge, being the primary cause of premature deaths and disabilities in all nations. ${ }^{150,173,197}$ This is a complicated and not 
just a health service-related issue because many NCDs are disorders that reflect the cumulative effects of individual behaviors and lifestyle choices combined with environmental and socio-economic risk factors. ${ }^{198,199}$ Because of the complexity of factors influencing the acquisition and course of NCDs, an holistic, systems-wide approach to their prevention and control is required. This has proved effective in those countries which have a strong PHC system coupled with good public health and secondary care system. ${ }^{89-93}$ A condition or disease is usually referred to as chronic or long-term after a long latency period with no definitive cure. The course of these diseases varies, with most individuals seeing gradual changes and deterioration over time, but which can lead to the failure of the organ(s) affected. ${ }^{200}$ Currently, chronic diseases are predominantly managed within a clinical care model based on a biomedical system of classification, complaint, history taking, physical examination, investigations if needed for diagnosis, treatment, prognosis, and management plan. ${ }^{201}$ However, this type of clinical care model is insufficient for the prevention and long-term control of incurable NCDs and requires more comprehensive care centralizing $\mathrm{PHC}$ as the lynchpin and coordinator of other services, including secondary care, public health and other social and community services. ${ }^{174,199}$

Conceptually and pragmatically, PHC provides the opportunity for communities to more easily access healthcare, which helps to ensure the equity, efficiency, effectiveness, safety, and timeliness of healthcare and empower individuals to achieve better health outcomes, which is essential for those with long term NCDs. ${ }^{30,202}$ A reliable PHC system that provides the first line point of healthcare to communities, drawing together knowledge, skills, and resources through inter-sectoral collaboration helps in the early detection, prevention, and control of NCDs. ${ }^{203}$ At an individual patient level, PHC systems record their longitudinal personal and medical history, which helps in the understanding of the disease development process, especially for long term conditions. ${ }^{204,205}$ A PHC approach can also identify and address the community health needs of various population groups and respond to geographical differences through acceptable, affordable, and accessible prevention and control measures. ${ }^{34,206}$ Globally, PHC approaches have led to many achievements in public health in the last 50 years. $^{207}$ Whilst much work is still needed to combat NCDs (primarily due to lifestyle factors such as obesity, sedentary lives, and poor diets) great strides have been made in the prevention and control of infectious diseases, which has helped to increase life expectancy and reduce maternal and infant mortality, particularly in the LMICs. ${ }^{207-211}$

Where a PHC approach has been most influential is in those health systems which are wholly or primarily in the public sector, but this does not reflect the reality in many systems, in which various proportions of healthcare services are privatized, governed by the corporate sector, often urban-based, and dominated by clinical activities which take a cost-benefit approach to care rather than focusing on a preventive and holistic system approach..$^{212-215}$ For NCDs, and for patients with long term conditions, a privatized, market-based approach to healthcare provision can lead to the poorer quality of care and can be very costly, especially when health insurance fails to address long-term or expensive health needs, such as medications or home care. $^{150,173,216-219}$

In many countries, especially those struggling economically, such as LMICs, all budgets are squeezed, and for healthcare, the focus tends to be on more highprofile acute service provision rather than prevention and control programs. ${ }^{220,221}$ All countries are also struggling with adapting to the significant socio-economic, lifestyle, and demographic shifts, including increased life expectancy, urbanization, environmental degradation, sedentary lives, personal risk behaviors, and changes in food habits. Overall, healthcare services have not adapted well to address long term and chronic diseases and NCDs, which are almost an "epidemic" in many LMICs. ${ }^{222,223}$ For many LMICs, whilst the PHC approach has not succeeded in meeting the health demands of ordinary people at an acceptable level, corporate-run costly privatized hospitals are not accessible and affordable to the general public either, which can lead to long term NCDs being undiagnosed and poorly managed, especially people who are more marginalized (eg, refugees, those living in poverty) or live in remote or rural areas. ${ }^{214,224,225}$ As discussed earlier, long term NCDs make a considerable contribution to overall mortality and morbidity in $\mathrm{LMICs}^{173,226}$ and although PHC has proven effective in preventing and controlling infectious diseases and in reducing maternal and child morbidities and mortality, ${ }^{52,227}$ it has yet to make significant inroads in reducing the impact of NCDs in LMICs. All countries who signed the Alma Ata declaration in 1978 expressed their commitment to implement a PHC approach to ensure the health of ordinary people ${ }^{55}$ and PHC clearly has a central role to play in improving the 
health of people with NCDs. However, political commitment is needed to enact the public's right to access to healthcare through active participation in healthcare activities. ${ }^{30,228}$ A comprehensive PHC approach should achieve more equitable, lower-cost quality health care for ordinary people living with NCDs and help reduce mortality and morbidity through active community participation, intersectoral-collaboration, and community empowerment. ${ }^{1,52,55,157,174,229,230}$

Communities should be made aware that NCDs can be prevented through the various levels, namely primary, secondary, and tertiary levels of prevention. ${ }^{230,231}$ The fundamental level of prevention is to stop the development of diseases, mainly through health promotion and lifestyle changes, which should be part of PHC services. ${ }^{232}$ Screening, another activity primarily carried out under the PHC services, is part of the secondary level of prevention for the early detection and prompt treatment of diseases to prevent the development of complications. This emphasizes that prevention does not stop even when diseases have developed. ${ }^{233}$ Similarly, tertiary prevention is essential for the rehabilitation of patients who suffer complications of NCDs. If carried out properly, these different levels of prevention should not only be able to reduce the morbidity and mortality from the NCDs but also improve patients' quality of life. ${ }^{174,231,234}$ Improved intersectoral collaboration and coordination between different stakeholders of healthcare has already occurred in many LMICs which has subsequently led to improvements in PHC and access to equitable healthcare ${ }^{128,132}$ and it has been suggested that other LMICs would benefit, particularly in relation to tackling the burden of NCDs, by adopting similar strategies. ${ }^{52,162,230}$ Effective long-term (chronic) disease management, requires a strong collaboration between all healthcare stakeholders, empowerment of communities, educational interventions for both providers and consumers, with focused, positive political decisionmaking and resource allocation to ensure all people from LMICs have equitable access to high quality preventive and healthcare services. ${ }^{235-238}$ Primary health care is central to achieving this in LMICs.

\section{Key Findings}

- NCDs are increasing in LMICs, causing increased morbidity and premature deaths in their populations;

- There is an urgent need for intersectoral collaboration among all stakeholders in the healthcare and broader systems;
- PHCs have already been successful in the prevention and control of NCDs in some LMICs;

- A PHC approach is essential in the prevention of NCDs through intersectoral comprehensive collaboration and emphasis on health equity.

\section{Acknowledgments}

The principal authors are very grateful to the Library of UPNM for its support in providing manuscripts that are not open access.

\section{Author Contributions}

Substantial contributions to conception and design, acquisition of data, or analysis and interpretation of data: $\mathrm{MH}$, TI, JM, NAAR, AA, SD; Drafting the article or revising it critically for important intellectual content: MH, TI, JM, NAAR, AA, SD; Final approval of the version to be published: MH, TI, JM, NAAR, AA, SD; Agreement to be accountable for all aspects of the work in ensuring that questions related to the accuracy or integrity of any part of the work are appropriately investigated and resolved: $\mathrm{MH}$, TI, JM, NAAR, AA, SD; Project administration: MH, TI, JM, NAAR, AA, SD.

\section{Funding}

This review manuscript received no financial support.

\section{Disclosure}

The authors report no conflicts of interest.

\section{References}

1. Tapela NM, Tshisimogo G, Shatera BP, et al. Integrating noncommunicable disease services into primary health care, Botswana. Bull World Health Organ. 2019;97(2):142-153. doi:10.2471/BLT.18.22 1424

2. Institute for Health Metrics and Evaluation (IHME). Findings from the Global Burden of Disease Study 2017; 2018. Seattle, WA:IHME. Available from: http://www.healthdata.org/sites/default/files/files/pol icy_report/2019/GBD_2017_Booklet.pdf. Accessed May 25, 2019.

3. Pervaiz R, Ercantan Ö. The burden of non-communicable diseases in relation to economic status of countries. Biomed Res Ther. 2018;5 (1):1967-1974. doi:10.15419/bmrat.v5i1.411

4. World Health Organization. Noncommunicable diseases. Key Facts; 2018. Available from: https://www.who.int/news-room/fact-sheets/ detail/noncommunicable-diseases. Accessed May 25, 2019.

5. Thomas B, Gostin LO. Tackling the Global NCD Crisis: innovations in Law and Governance. J Law Med Ethics. 2013;41(1):16-27. doi:10. $1111 / \mathrm{jlme} .12002$

6. Hwang CK, Han PV, Zabetian A, Ali MK, Narayan KM. Rural diabetes prevalence quintuples over twenty-five years in low- and middle-income countries: a systematic review and meta-analysis. Diabetes Res Clin Pract. 2012;96(3):271-285. doi:10.1016/j. diabres 
7. World Health Organization. Global Action Plan for the Prevention and Control of NCDs 2013-2020. Noncommunicable diseases and mental health; 2013. Available from: https://apps.who.int/ iris/bitstream/handle/10665/94384/9789241506236_eng.pdf;jses sionid $=\mathrm{ADC} 4 \mathrm{~B} 43 \mathrm{EF} 48 \mathrm{FCF} 4333 \mathrm{~B} 1 \mathrm{DD} 0 \mathrm{CB} 8 \mathrm{E} 983 \mathrm{DC}$ ?sequence $=$ 1. Accessed May 25, 2019.

8. Miranda JJ, Kinra S, Casas JP, Smith GD, Ebrahim S. Non-communicable diseases in low- and middle-income countries: context, determinants, and health policy. Trop Med Int Health. 2008;13 (10):1225-1234. doi:10.1111/j.1365-3156.2008.02116.x

9. Allen LN. Financing national non-communicable disease responses. Glob Health Action. 2012;10(1):1326687. doi:10.1080/ 16549716.2017.1326687

10. Essue BM, Laba M, Knaul F, et al. Economic burden of chronic ill health and injuries for households in low- and middle-income countries. In: Jamison DT, Gelband H, Horton S, et al. editors. Disease Control Priorities: Improving Health and Reducing Poverty. 3rd. Washington (DC): The International Bank for Reconstruction and Development/The World Bank; 2017. Available from https://www.ncbi.nlm.nih.gov/books/NBK525297/. Accessed May 25, 2019.

11. Norbeck TB. Drivers of health care costs. A Physicians Foundation white paper - second of a three-part series. Mo Med. 2013;110 (2):113-118

12. Bauer UE, Briss PA, Goodman RA, Bowman BA. Prevention of chronic disease in the 21st century: elimination of the leading preventable causes of premature death and disability in the USA. Lancet. 2014;384(9937):45-52. doi:10.1016/S0140-6736(14)60648-6

13. McPhail SM. Multimorbidity in chronic disease: impact on health care resources and costs. Risk Manag Healthc Policy. 2016;9:143156. doi:10.2147/RMHP.S 97248

14. World Health Organization. 2008-2013 Action Plan for the Global Strategy for the Prevention and Control of Noncommunicable Diseases. WHO Press, World Health Organization, 20 Avenue Appia, 1211 Geneva 27, Switzerland; 2008. Available from: https://www.who.int/nmh/publications/ncd_action_plan_en.pdf Accessed May 25, 2019.

15. World Health Organization. WHO tools to prevent and control noncommunicable diseases? Noncommunicable diseases and mental health. 2013. Available from: https://www.who.int $/ \mathrm{nmh} / \mathrm{ncd}-$ tools/en/. Accessed May 25, 2019

16. World Health Organization. Global action plan for the prevention and control of noncommunicable diseases 2013-2020. WHO Press, World Health Organization, 20 Avenue Appia, 1211 Geneva 27, Switzerland. Available from: http://africahealthforum.afro.who.int/ first-edition/IMG/pdf/global_action_plan_for_the_prevention_and control_of_ncds_2013-2020.pdf. Accessed May 25, 2019.

17. Starfield B, Shi L, Macinko J. Contribution of primary care to health systems and health. Milbank Q. 2005;83(3):457-502. doi:10.1111/j.1468-0009.2005.00409.x

18. Bitton A, Ratcliffe HL, Veillard JH, et al. Primary health care as a foundation for strengthening health systems in low- and middleincome countries. J Gen Intern Med. 2017;32(5):566-571. doi:10. 1007/s11606-016-3898-5

19. The National Health Service. The Dawson report 1920. 2001. Available from: https://www.historyofsurgery.co.uk/history/html/ hnhs06.html. Accessed May 31, 2019.

20. Frenk J. Reinventing primary health care: the need for systems integration. Lancet. 2009;374(9684):170-173. doi:10.1016/S01406736(09)60693-0

21. Ministry of Health. Consultative Council on Medical and Allied Services. Interim Report on the Future Provision of Medical and Allied Services. Presented to Parliament by Command of His Majesty. London Published by His Majesty's Stationery Office; 1920. Available from: http://www.nhshistory.net/Dawson\% 20report.html. Accessed June 1, 2019.
22. [No authors listed]. Dawson Report: sixty years after the high hopes of 1920. Health Soc Serv J. 1980;90(4693):638-640.

23. Beales JG. Dawson Report: the centers of discontent. Health Soc Serv J. 1980;90(4693):644-645.

24. Bashshur RL, Howell JD, Krupinski EA, Harms KM, Bashshur N, Doarn CR. The empirical foundations of telemedicine interventions in primary care. Telemed $J$ E Health. 2016;22(5):342-375. doi:10.1089/tmj.2016.0045

25. Gorsky M. The British National Health Service 1948-2008: a review of the historiography. Soc Hist Med. 2008;21(3):437-460. doi:10.1093/shm/hkn064

26. World Health Organization. From Alma-Ata to the Year 2000: Reflections at the Midpoint. Geneva, Switzerland; 1988:110. Available from: https://apps.who.int/iris/bitstream/handle/10665/ 39323/9241561246_eng.pdf? sequence $=1 \&$ isAllowed $=y$. Accessed May 26, 2019

27. Litsios S. On the origin of primary health care. In: Medcalf A, Bhattacharya $\mathrm{S}$, Momen $\mathrm{H}$, et al. editors. Health for All: The Journey of Universal Health Coverage. Hyderabad (IN): Orient Blackswan; 2015. Chapter 1. Available from: https://www.ncbi. nlm.nih.gov/books/NBK316278/. Accessed May 26, 2019.

28. Bitton A, Fifield J, Ratcliffe H, et al. Primary healthcare system performance in low-income and middle-income countries: a scoping review of the evidence from 2010 to 2017. BMJ Glob Health. 2019;4(Suppl 8):e001551. doi:10.1136/bmjgh-2019-001551

29. Tapp H, Dulin M. The science of primary health-care improvement: potential and use of community-based participatory research by practice-based research networks for translation of research into practice. Exp Biol Med (Maywood). 2010;235(3):290-299. doi:10. 1258/ebm.2009.009265

30. Sambala EZ, Sapsed S, Mkandawire ML. Role of primary health care in ensuring access to medicines. Croat Med J. 2010;51 (3):181-190. doi:10.3325/2010.51.181

31. Rifkin SB Health for all and primary health care, 1978-2018: a historical perspective on policies and programs over 40 years. Oxford research encyclopedia of global public health, Oxford University Press USA; 2019. Available from: https://oxfordre. com/publichealth/view/10.1093/acrefore/9780190632366.001. 0001/acrefore-9780190632366-e-55?print=pdf. Accessed May 26, 2019.

32. Rifkin SB. Alma Ata, after 40 years: primary Health Care and Health for All-from consensus to complexity. BMJ Glob Health. 2018;3:e01188. doi:10.1136/bmjgh-2018-001188

33. World Health Organization. Constitution of the World Health Organization Basic Documents, Forty-fifth edition, Supplement; 2006. Available from: https://www.who.int/governance/eb/who_ constitution_en.pdf. Accessed May 26, 2019.

34. White F. Primary health care and public health: foundations of universal health systems. Med Princ Pract. 2015;24(2):103-116. doi: $10.1159 / 000370197$

35. World Health Organization. Health Statistics and information systems; 2020. Available from: https://www.who.int/healthinfo/glo bal_burden_disease/metrics_daly/en/. Accessed February 18, 2020.

36. Oni $\mathrm{T}$, Unwin $\mathrm{N}$. Why the communicable/non-communicable disease dichotomy is problematic for public health control strategies: implications of multimorbidity for health systems in an era of health transition. Int Health. 2015;7(6):390-399. doi:10.1093/ inthealth/ihv040

37. Sommer I, Griebler U, Mahlknecht P, et al. Socioeconomic inequalities in non-communicable diseases and their risk factors: an overview of systematic reviews. BMC Public Health. 2015;15:914. doi:10.1186/s12889-015-2227-y

38. Wamai RG, Kengne AP, Levitt N. Non-communicable disease surveillance: overview of magnitude and determinants in Kenya from STEPwise approach survey of 2015. BMC Public Health. 2018;18(Suppl 3):1224. doi:10.1186/s12889-018-6051-z 
39. Isere EE, Fatiregun AA, Ajayi IO. An overview of disease surveillance and notification system in Nigeria and the roles of clinicians in disease outbreak prevention and control. Niger Med J. 2015;56 (3):161-168. doi:10.4103/0300-1652.160347

40. Haque M, McKimm J, Godman B, Abu Bakar M, Sartelli M. Initiatives to reduce postoperative surgical site infections of the head and neck cancer surgery with a special emphasis on developing countries. Expert Rev Anticancer Ther. 2019;19(1):81-92. doi: $10.1080 / 14737140.2019 .1544497$

41. GBD 2016 Causes of Death Collaborators. Global, regional, and national age-sex specific mortality for 264 causes of death, 1980-2016: a systematic analysis for the Global Burden of Disease Study 2016. Lancet. 2017;390(10100):1151-1210. doi:10. 1016/S0140-6736(17)32152-9.

42. Ali M, Park JK, von Seidlein L, Acosta CJ, Deen JL, Clemens JD. Organizational aspects and implementation of data systems in large-scale epidemiological studies in less developed countries. BMC Public Health. 2006;6:86. doi:10.1186/1471-2458-6-86

43. Remais JV, Zeng G, Li G, Tian L, Engelgau MM. Convergence of non-communicable and infectious diseases in low- and middleincome countries. Int $J$ Epidemiol. 2013;42(1):221-227. doi:10. 1093/ije/dys 135

44. Rodriguez-Fernandez R, Ng N, Susilo D, Prawira J, Bangs MJ, Amiya RM. The double burden of disease among mining workers in Papua, Indonesia: at the crossroads between Old and New health paradigms. BMC Public Health. 2016;16(1):951. doi:10.1186/ s12889-016-3630-8

45. Boutayeb A. The double burden of communicable and non-communicable diseases in developing countries. Trans $R$ Soc Trop Med Hyg. 2006;100(3):191-199. doi:10.1016/j.trstmh.2005.07.021

46. Peltzer K. Tuberculosis non-communicable disease comorbidity and multimorbidity in public primary care patients in South Africa. Afr J Prim Health Care Fam Med. 2018;10(1):e1-e6. doi:10.4102/phcfm.v10i1.1651

47. Kaveeshwar SA, Cornwall J. The current state of diabetes mellitus in India. Australas Med J. 2014;7(1):45-48. doi:10.4066/AMJ.2013.1979

48. Engelgau MM, El-Saharty S, Kudesia P, Rajan V, Rosenhouse S, Okamoto $\mathrm{K}$ Capitalizing on the demographic transition: tackling noncommunicable diseases in South Asia. 1818 H Street NW, Washington DC, USA. The World Bank; 2011. Available from: https://openknowledge.worldbank.org/bitstream/handle/10986/ 2343/622600REPLACEM0blic00use0same0info0.pdf? sequence= 1\&isAllowed=y. Accessed May 26, 2019.

49. Yang W, Lu J, Weng J, et al.; China National Diabetes and Metabolic Disorders Study Group. Prevalence of diabetes among men and women in China. $N$ Engl J Med. 2010;362(12):10901101. doi:10.1056/NEJMoa0908292.

50. Raviglione M, Sulis G. Tuberculosis 2015: burden, challenges, and strategy for control and elimination. Infect Dis Rep. 2016;8 (2):6570. doi:10.4081/idr.2016.6570

51. World Health Organization. Global tuberculosis 2018 Report. Executive summary; 2018. Available from: https://www.who.int/ tb/publications/global_report/tb18_ExecSum_web_4Oct18.pdf. Accessed May 26, 2019.

52. Demaio AR, Kragelund Nielsen K, Pinkowski Tersbøl B, Kallestrup P, Meyrowitsch DW. Primary Health Care: a strategic framework for the prevention and control of chronic non-communicable disease. Glob Health Action. 2014;7:24504. doi:10.3402/gha.v7.24504

53. Panda R, Mahapatra S, Persai D. Health system preparedness in noncommunicable diseases: findings from two states Odisha and Kerala in India. J Family Med Prim Care. 2018;7(3):565-570. doi:10.4103/jfmpc.jfmpc_111_17

54. Kane J, Landes M, Carroll $\bar{C}$, Nolen A, Sodhi S. A systematic review of primary care models for non-communicable disease interventions in Sub-Saharan Africa. BMC Fam Pract. 2017;18 (1):46. doi:10.1186/s12875-017-0613-5
55. World Health Organization. WHO called to return to the Declaration of Alma-Ata? Social determinants of health. Available from: https://www.who.int/social_determinants/tools/mul timedia/alma_ata/en/. Accessed June 9, 2019.

56. Victorian Order of Nurses of Canada. Principles of Primary Health Care. 2315 St. Laurent Blvd, Suite 100, Ottawa, ON K1G 4J8, Canada; 2018. Available from: http://von.ca/en/principles-primaryhealth-care. Accessed June 9, 2019.

57. World Health Organization. NCD mortality and morbidity. Global Health Observatory (GHO) data. Available from: https://www.who. int/gho/ncd/mortality_morbidity/en/. Accessed June 2, 2019.

58. World Health Organization. Global status report on noncommunicable diseases 2010. WHO Press, World Health Organization, 20 Avenue Appia, 1211 Geneva 27, Switzerland; 2011. Available from: https://www.who.int $/ \mathrm{nmh} /$ publications/ncd_report_full_en. pdf. Accessed June 2, 2019.

59. Gowshall M, Taylor-Robinson SD. The increasing prevalence of non-communicable diseases in low-middle income countries: the view from Malawi. Int J Gen Med. 2018;11:255-264. doi:10.2147/ IJGM.S157987

60. Boutayeb A, Boutayeb S. The burden of non-communicable diseases in developing countries. Int J Equity Health. 2005;4(1):2. doi:10.1186/1475-9276-4-2

61. World Health Organization. Noncommunicable Diseases (NCD) Country Profiles: Malawi; 2014. Available from: http://www.who. int/nmh/countries/mwi_en.pdf. Accessed June 2, 2019.

62. Pastakia SD, Pekny CR, Manyara SM, Fischer L. Diabetes in subSaharan Africa - from policy to practice to progress: targeting the existing gaps for future care for diabetes. Diabetes Metab Syndr Obes. 2017;10:247-263. doi:10.2147/DMSO.S126314

63. Nyaaba GN, Stronks K, De-graft Aikins A, Kengne AP, Agyemang C. Tracing Africa's progress towards implementing the NonCommunicable Diseases Global action plan 2013-2020: a synthesis of WHO country profile reports. BMC Public Health. 2017;17 (1):297. doi:10.1186/s12889-017-4199-6

64. Arokiasamy P. India's escalating burden of non-communicable diseases. Lancet Glob Health. 2018;6(12):e1262-e1263. doi:10.10 16/S2214-109X(18)30448-0

65. Upadhyay RP. An overview of the burden of non-communicable diseases in India. Iran J Public Health. 2012;41(3):1-8.

66. Nethan S, Sinha D, Mehrotra R. Non-communicable disease risk factors and their trends in India. Asian Pac J Cancer Prev. 2017;18 (7):2005-2010. doi:10.22034/APJCP.2017.18.7.2005

67. India State-Level Disease Burden Initiative Collaborators. Nations within a nation: variations in epidemiological transition across the states of India, 1990-2016 in the global burden of disease study. Lancet. 2017;390:2437-2460. doi:10.1016/S01406736(17)32804-0

68. India State-Level Disease Burden Initiative CVD Collaborators. The changing patterns of cardiovascular diseases and their risk factors in the states of India: the Global Burden of Disease Study 1990-2016. Lancet Glob Health. 2018;6(12):e1339-e1351. doi:10. 1016/S2214-109X(18)30407-8.

69. Barrett B. Integrated local health systems in Central America. Soc Sci Med. 1996;3(1):71-82. doi:10.1016/0277-9536(95)00336-3

70. Salvi S, Kumar GA, Dhaliwal RS; India State-Level Disease Burden Initiative CRD Collaborators. The burden of chronic respiratory diseases and their heterogeneity across the states of India: the Global Burden of Disease Study 1990-2016. Lancet Glob Health. 2018;6(12):e1363-e1374. doi:10.1016/S2214-109X (18)30409-1

71. Tandon N, Anjana RM, Mohan V; India State-Level Disease Burden Initiative Diabetes Collaborators. The increasing burden of diabetes and variations among the states of India: the Global Burden of Disease Study 1990-2016. Lancet Glob Health. 2018;6 (12):e1352-e1362. doi:10.1016/S2214-109X(18)30387-5 
72. Dey S Non-communicable diseases cause $61 \%$ of deaths in India: WHO report. Times of India. E Times; 2017. Available from: https://timesofindia.indiatimes.com/life-style/health-fitness/healthnews/non-communicable-diseases-cause-61-of-deaths-in-indiawho-report/articleshow/60761288.cms. Accessed June 6, 2019.

73. World Health Organization. Priority noncommunicable diseases and conditions. Chapter 8. WHO Office for Western Pacific Region; 2008. Available from: http://www.wpro.who.int/health research/documents/dhs_hr_health_in_asia_and_the_pacific_13_ chapter_8_priority_noncommunicable_diseases_and_disorders.pdf. Accessed June 6, 2019.

74. World Health Organization. NCDs Mortality. NCD and Tobacco Surveillance. Regional Office of South East Asia; 2019. Available from: http://www.searo.who.int/entity/ncd tobacco surveillance/ data/ncd_mortality/en/. Accessed June 6, 2019.

75. World Health Organization. Pan American Health Organization. Health Status of the Population Mortality in the Americas. Regional Office for the Americas of the World Health Organization, 525 Twenty-third Street, N.W., Washington, D.C. 20037, United States of America. Available from: https://www.paho.org/salud-en-las-amer icas-2017/?p=1457. Accessed June 8, 2019.

76. Perel P, Casas JP, Ortiz Z, Miranda JJ. Noncommunicable diseases and injuries in Latin America and the Caribbean: time for action. PLoS Med. 2006;3(9):e344. doi:10.1371/journal.pmed.0030344

77. Branca F, Lartey A, Oenema S, et al. Transforming the food system to fight non-communicable diseases. BMJ. 2019;364:1296. doi:10.1136/ bmj.1296

78. Lopez AD, Mathers CD, Ezzati M, Jamison DT, Murray CJ. Global and regional burden of disease and risk factors, 2001: systematic analysis of population health data. Lancet. 2006;367(9524):17471757. doi:10.1016/S0140-6736(06)68770-9

79. World Health Organization. Declaration of Alma Ata. World Health Organization; 2000. Available from: http://www.who.int/publica tions/almaata_declaration_en.pdf. Accessed May 31, 2019.

80. Rao M, Pilot E. The missing link-the role of primary care in global health. Glob Health Action. 2014;7:23693. doi:10.3402/gha.v7.23693

81. Thomas S, Beh L, Nordin RB. Health care delivery in Malaysia: changes, challenges, and champions. J Public Health Afr. 2011;2 (2):e23. doi:10.4081/jphia.2011.e23

82. Doherty J, Govender R. The Cost-Effectiveness of Primary Care Services in Developing Countries: A Review of the International Literature. Washington: World Bank, World Health Organization, Fogarty International Centre of the U.S. National Institutes of Health; 2004.

83. Ahmed NU, Alam MM, Sultana F, Sayeed SN, Pressman AM, Powers MB. Reaching the unreachable: barriers of the poorest to accessing NGO healthcare services in Bangladesh. J Health Popul Nutr. 2006;24(4):456-466.

84. Institute of Medicine (US) Committee on Understanding and Eliminating Racial and Ethnic Disparities in Health Care; Smedley BD, Stith AY, Nelson AR, editors. Unequal Treatment: Confronting Racial and Ethnic Disparities in Health Care. Washington (DC): National Academies Press (US); 2003:2. The Healthcare Environment and Its Relation to Disparities. Available from: https://www.ncbi.nlm. nih.gov/books/NBK220362/. Accessed May 31, 2019

85. Barik D, Thorat A. Issues of Unequal Access to Public Health in India. Front Public Health. 2015;3:245. doi:10.3389/fpubh.2015. 00245

86. De Maeseneer J, Willems S, De Sutter A, Van de Geuchte I, Billings M Primary health care as a strategy for achieving equitable care: a literature review commissioned by the Health Systems Knowledge Network. The Health Systems Knowledge Network, the WHO Commission on the Social Determinants of Health from September 2005 to March 2007; 2007. Available from: https://www.who.int/social_determinants/resources/csdh_media/pri mary_health_care_2007_en.pdf. Accessed May 31, 2019.
87. Kringos DS, Boerma W, van der Zee J, Groenewegen P. Europe's strong primary care systems are linked to better population health but also to higher health spending. Health Aff (Millwood). 2013;32 (4):686-694. doi:10.1377/hlthaff.2012.1242

88. Hansen J, Groenewegen PP, Boerma WG, Kringos DS. Living in a country with a strong primary care system is beneficial to people with chronic conditions. Health Aff (Millwood). 2015;34(9):15311537. doi:10.1377/hlthaff.2015.0582

89. Pineault R, Levesque JF, Roberge D, Hamel M, Lamarche P, Haggerty J. Population Health and Health Services Team. Accessibility and Continuity of Care: A Study of Primary Healthcare in Québec. Research Report Presented to the Canadian Institutes of Health Research (CIHR) and the Canadian Health Services Research Foundation (CHSRF); 2009. Available from: ht t p s://www.ins pq.qc.ca/pdf/publications/911 ServicesPremLigneANGLAIS.pdf. Accessed June 1, 2019.

90. Pineault R, Provost S, Hamel M, Couture A, Levesque JF. The influence of primary health care organizational models on patients' experience of care in different chronic disease situations. Chronic Dis Inj Can. 2011;31(3):109-120.

91. Eersel MG, Vreden SG, van Eer ED, Mans DR. Fifty years of primary health care in the rainforest: temporal trends in morbidity and mortality in indigenous Amerindian populations of Suriname. J Glob Health. 2018;8(2):020403. doi:10.7189/jogh. 08.020403

92. Atun RA What are the advantages and disadvantages of restructuring a health care system to be more focused on primary care services? Network Report. Copenhagen: WHO; 2004. Available from: http://www.euro.who.int/__data/assets/pdf_file/0004/74704/ E82997.pdf. Accessed June 1, 2019.

93. Lee A, Kiyu A, Milman HM, Jimenez J. Improving health and building human capital through an effective primary care system. $J$ Urban Health. 2007;84(3 Suppl):i75-i85. doi:10.1007/s11524-0079175-5

94. Freeman T, Baum F, Lawless A, et al. Case study of an aboriginal community-controlled health service in Australia: universal, rightsbased, publicly funded comprehensive primary health care in action. Health Hum Rights. 2016;18(2):93-108.

95. Baum F, Freeman T, Lawless A, Labonte R, Sanders D. What is the difference between comprehensive and selective primary health care? Evidence from a five-year longitudinal realist case study in South Australia. BMJ Open. 2017;7:e015271. doi:10.1136/bmjopen-2016-015271

96. Costello M, Taylor J, O'Hara L. Impact evaluation of a health promotion-focused organizational development strategy on a health service's capacity to deliver comprehensive primary health care. Aust J Prim Health. 2015;21(4):444-449. doi:10.10 71/PY14107

97. Mayberry RM, Nicewander DA, Qin H, Ballard DJ. Improving quality and reducing inequities: a challenge in achieving best care. Proc (Bayl Univ Med Cent). 2006;19(2):103-118. doi:10. 1080/08998280.2006.11928138

98. Amofah GK. Ghana. Selective versus comprehensive primary health care. Trop Doct. 1994;24(2):76-78. doi:10.1177/00494755 9402400212

99. Magnussen L, Ehiri J, Jolly P. Comprehensive versus selective primary health care: lessons for global health policy. Health Aff (Millwood). 2004;23(3):167-176. doi:10.1377/hlthaff.23.3.167

100. Djukanovic V, Mach E. Alternative Approaches to Meeting Basic Health Needs in Developing Countries. Geneva: WHO \& UNICEF; 1975.

101. Diaz-Briquets S. The Health Revolution in Cuba. 1st ed. Austin: University of Texas Press; 1983.

102. Huish R, Kirk JM; Cuban Medical. Internationalism and the Development of the Latin American School of Medicine. Lat Am Perspect. 2007;34(6):77-99. doi:10.1177/0094582X07308119 
103. World Health Organization. A glossary of terms for community health care and services for older persons. World Health Organization Kobe Centre, Japan. WHO Centre for Health Development; 2004. Available from: http://www.who.int/kobe_centre/ageing/ahp_vol5_glossary.pdf. Accessed June 22, 2019.

104. World Health Organization. Package of essential noncommunicable (PEN) disease interventions for Primary Health Care in LowResource Settings. WHO Press, World Health Organization, 20 Avenue Appia, 1211 Geneva 27, Switzerland. Available from: https://www.who.int/nmh/publications/essential_ncd_interven tions_lr_settings.pdf. Accessed June 22, 2019.

105. World Health Organization. Global NCD target improves access to technologies and medicines to treat NCDs; 2016. Available from: https://www.who.int/beat-ncds/take-action/policy-brief-improvemedicine-access.pdf. Accessed June 22, 2019.

106. Mendis S. The policy agenda for prevention and control of noncommunicable diseases. Br Med Bull. 2010;96:23-43. doi:10.1093/ bmb/ldq037

107. Mwangome M, Geubbels E, Klatser P, Dieleman M. Perceptions on diabetes care provision among health providers in rural Tanzania: a qualitative study. Health Policy Plan. 2017;32(3):418-429. doi:10.1093/heapol/czw143

108. Katende D, Mutungi G, Baisley K, et al. Readiness of Ugandan health services for the management of outpatients with chronic diseases. Trop Med Int Health. 2015;20(10):1385-1395. doi:10.1111/tmi.12560

109. Ren J, Liu C, Gao QS, Yang L, Huang X, Guo Q. Use of appropriate healthcare technologies: a cross-sectional study in rural Zhejiang of China. BMC Health Serv Res. 2015;15:295. doi:10.1186/s12913-015-0947-4

110. Elias MA, Pati MK, Aivalli P, et al. Preparedness for delivering non-communicable disease services in primary care: access to medicines for diabetes and hypertension in a district in south India. BMJ Glob Health. 2018;2(Suppl 3):e000519. doi:10.1136/ bmjgh-2017-000519

111. Heine M, Fell BL, Robinson A, Abbas M, Derman W, Hanekom S. Patient-centered rehabilitation for non-communicable disease in a low-resource setting: study protocol for a feasibility and proof-ofconcept randomized clinical trial. BMJ Open. 2019;9(4):e025732. doi:10.1136/bmjopen-2018-025732

112. Young HM, Nesbitt TS. Increasing the capacity of primary care through enabling technology. J Gen Intern Med. 2017;32(4):398403. doi:10.1007/s11606-016-3952-3

113. Rothman AA, Wagner EH. Chronic illness management: what is the role of primary care? Ann Intern Med. 2003;138(3):256-261. doi:10.7326/0003-4819-138-3-200302040-00034

114. Milani RV, Bober RM, Lavie CJ. The role of technology in chronic disease care. Prog Cardiovasc Dis. 2016;58(6):579-583. doi:10.1016/j.pcad.2016.01.001

115. Rhudy C, Broxterman J, Stewart S, et al. Improving patient portal enrolment in an academic resident continuity clinic: quality improvement made simple. BMJ Open Qual. 2019;8(2):e000430. doi:10.1136/bmjoq-2018-000430

116. Kruk ME, Porignon D, Rockers PC, et al. The contribution of primary care to health and health systems in low- and middle-income countries: a critical review of major primary care initiatives. Soc Sci Med. 2010;70:904-911. doi:10.1016/j.socscimed.2009.11.025

117. Dodd R, Palagyi A, Jan S, et al. Organization of primary health care systems in low- and middle-income countries: review of evidence on what works and why in the Asia-Pacific region. $B M J$ Glob Health. 2019;4:e001487. doi:10.1136/bmjgh-2019-001487

118. Veillard J, Cowling K, Bitton A, et al. Better Measurement for Performance Improvement in Low- and Middle-Income Countries: the Primary Health Care Performance Initiative (PHCPI) Experience of Conceptual Framework Development and Indicator Selection. Milbank Q. 2017;95(4):836-883. doi:10.1111/1468-0009.12301
119. Druetz T. Integrated primary health care in low- and middleincome countries: a double challenge. BMC Med Ethics. 2018;19 (Suppl S1):48. doi:10.1186/s12910-018-0288-z

120. Baum F, Freeman T, Sanders D, Labonté R, Lawless A, Javanparast S. Comprehensive primary health care under neoliberalism in Australia. Soc Sci Med. 2016;168:43-52. doi:10.1016/j.socscimed.2016.09.005

121. Kreisel W, von Schirnding Y. Intersectoral action for health: a cornerstone for health-for-all in the twenty-first century. World Health Stat Q. 1998;51(1):75-78.

122. World Health Organization. Constitution of the World Health Organization. The Constitution was adopted by the International Health Conference held in New York from 19 June to 22 July 1946, signed on 22 July 1946 by the representatives of 61 States (Off. Rec. Wld Hlth Org., 2100), and entered into force on 7 April 1948. Amendments adopted by the Twenty-sixth, Twenty-ninth, Thirtyninth, and Fifty-first World Health Assemblies (resolutions WHA26.37, WHA29.38, WHA39.6 and WHA51.23) came into force on 3 February 1977, 20 January 1984, 11 July 1994 and 15 September 2005 respectively and are incorporated in the present text. Available from: https://www.who.int/governance/eb/who_con stitution_en.pdf. Accessed June 9, 2019.

123. Adeleye OA, Ofili AN. Strengthening intersectoral collaboration for primary health care in developing countries: can the health sector play broader roles? J Environ Public Health. 2010; 2010:272896. doi:10.1155/2010/272896

124. Rantala R, Bortz M, Armada F. Intersectoral action: local governments promoting health. Health Promot Int. 2014;29(Suppl 1):i92102. doi:10.1093/heapro/dau047

125. Thomas P. Welcome to the London journal of primary care. London $J$ Prim Care (Abingdon). 2008;1(1):1-2. doi:10.1080/1757147 2.2008.11493180

126. World Health Organization. Multisectoral and intersectoral action for improved health and well-being for all: mapping of the WHO European Region. Governance for a sustainable future: improving health and well-being for all. Final Report. WHO Regional Office for Europe, UN City, Marmorvej 51, DK-2100 Copenhagen Ø, Denmark; 2018 Available from: http://www.euro.who.int/_data/ assets/pdf_file/0005/371435/multisectoral-report-h1720-eng.pdf? ua=1. Accessed June 10, 2019.

127. World Health Organization. Country Office for Nepal. Multisectoral Action Plan for the Prevention and Control of NonCommunicable Diseases (2014-2020). Government of Nepal. Available from: http://www.searo.who.int/nepal/mediacentre/ncd multisectoral_action_plan.pdf. Accessed June 10, 2019.

128. Bennett S, Glandon D, Rasanathan K. Governing multisectoral action for health in low-income and middle-income countries: unpacking the problem and rising to the challenge. BMJ Glob Health. 2018;3(Suppl 4): e000880. doi:10.1136/bmjgh-2018-000880

129. Rasanathan K, Atkins V, Mwansambo C, Soucat A, Bennett S. Governing multisectoral action for health in low-income and middleincome countries: an agenda for the way forward. BMJ Glob Health. 2018;3(Suppl 4):e000890. doi:10.1136/bmjgh-2018-000890

130. Shibuya K, Ciecierski C, Guindon E, Bettcher DW, Evans DB, Murray CJ; WHO Framework Convention on Tobacco Control. WHO framework convention on Tobacco control: development of an evidence-based global public health treaty. BMJ. 2003;327 (7407):154-157. doi:10.1136/bmj.327.7407.154

131. Staton C, Vissoci J, Gong E, et al. Road traffic injury prevention initiatives: a systematic review and meta summary of effectiveness in low- and middle-income countries. PLoS One. 2016;11(1): e0144971. doi:10.1371/journal.pone.0144971

132. Hall T, Kakuma R, Palmer L, Minas H, Martins J, Armstrong G. Intersectoral collaboration for people-centered mental health care in Timor-Leste: a mixed-methods study using qualitative and social network analysis. Int J Ment Health Syst. 2019;13:72. doi:10.1186/ s13033-019-0328-1 
133. Yarahmadi S, Etemad K, Hazaveh AM, Azhang N. Urbanization and non-communicable risk factors in the capital city of 6 big provinces of Iran. Iran J Public Health. 2013;42(Supple1):113-118.

134. Hancock C, Kingo L, Raynaud O. The private sector, international development, and NCDs. Global Health. 2011;7:23. doi:10.1186/ 1744-8603-7-23

135. Mustapha F, Omar Z, Mihat O, et al. Addressing non-communicable diseases in Malaysia: an integrative process of systems and community. BMC Public Health. 2014;14 Suppl 2(Suppl 2):S4. doi:10.1186/1471-2458-14-S2-S4

136. Smed S, Scarborough P, Rayner M, Jensen JD. The effects of the Danish saturated fat tax on food and nutrient intake and modeled health outcomes: an econometric and comparative risk assessment evaluation. Eur J Clin Nutr. 2016;70(6):681-686. doi:10.1038/ejcn.2016.6

137. Aldwell K, Caillaud C, Galy O, Frayon S, Allman-Farinelli M. Tackling the Consumption of High Sugar Products among Children and Adolescents in the Pacific Islands: implications for Future Research. Healthcare (Basel). 2018;6(3):81. doi:10.3390/healthcare6030081

138. Bergallo P, Castagnari V, Fernández A, Mejía R. Regulatory initiatives to reduce sugar-sweetened beverages (SSBs) in Latin America. PLoS One. 2018;13(10):e0205694. doi:10.1371/journal. pone.0205694

139. Ho LM, Schafferer C, Lee JM, Yeh CY, Hsieh CJ. Raising cigarette excise tax to reduce consumption in low-and-middle-income countries of the Asia-Pacific region: a simulation of the anticipated health and taxation revenues impacts. BMC Public Health. 2018;18(1):1187. doi:10.1186/s12889-018-6096-z

140. Schafferer C, Yeh CY, Chen SH, Lee JM, Hsieh CJ. A simulation impact evaluation of a cigarette excise tax increase on licit and illicit cigarette consumption and tax revenue in 36 European countries. Public Health. 2018;162:48-57. doi:10.1016/j.puhe.2018.05.017

141. Alvarez FN, Leys M, Mérida HE, Guzmán GE. Primary health care research in Bolivia: systematic review and analysis. Health Policy Plan. 2016;31(1):114-128. doi:10.1093/heapol/czv013

142. Ramírez NA, Ruiz JP, Romero RV, Labonté R. Comprehensive primary health care in South America: contexts, achievements, and policy implications. Cad Saude Publica. 2011;27(10):18751890. doi:10.1590/s0102-311x2011001000002

143. Saif-Ur-Rahman KM, Mamun R, Nowrin I, et al. Primary healthcare policy and governance in low-income and middle-income countries: an evidence gap map. BMJ Glob Health. 2019;4: e001453. doi:10.1136/bmjgh-2019-001453

144. Kironde S, Kahirimbanyi M. Community participation in primary health care (PHC) programs: lessons from tuberculosis treatment delivery in South Africa. Afr Health Sci. 2002;2(1):16-23.

145. McEvoy R, Tierney E, MacFarlane A. 'Participation is integral': understanding the levers and barriers to the implementation of community participation in primary healthcare: a qualitative study using normalization process theory. BMC Health Serv Res. 2019;19 (1):515. doi:10.1186/s12913-019-4331-7

146. Dooris M, Heritage Z. Healthy cities: facilitating the active participation and empowerment of local people. J Urban Health. 2013;90 Suppl 1(Suppl 1):74-91. doi:10.1007/s11524-011-9623-0

147. George AS, Mehra V, Scott K, Sriram V. Community participation in health systems research: a systematic review assessing the state of research, the nature of interventions involved and the features of engagement with communities. PLoS One. 2015;10(10):e141091. doi:10.1371/journal.pone.0141091

148. George AS, Scott K, Mehra V, Sriram V. Synergies, strengths, and challenges: findings on community capability from a systematic health systems research literature review. BMC Health Serv Res. 2016;16(Suppl 7):623. doi:10.1186/s12913-016-1860-1

149. Moore L, Chersich MF, Steen R, et al. Community empowerment and involvement of female sex workers in targeted sexual and reproductive health interventions in Africa: a systematic review. Global Health. 2014;10:47. doi:10.1186/1744-8603-10-47
150. Schmidt H. Chronic disease prevention and health promotion. In: Barrett DH, Ortmann LW, Dawson A, et al. editors. Public Health Ethics: Cases Spanning the Globe. Cham (CH): Springer; 2016. doi:10.1007/978-3-319-23847-0 5

151. Nandan D, Adhish VS, Dhar N. Relevance of primary health care in controlling noncommunicable diseases in India. Indian J Community Med. 2011;36(Suppl 1):S4-S6. doi:10.4103/0970-0218.94702

152. Morgan LM. Community participation in health: perpetual allure, persistent challenge. Health Policy Plan. 2001;16(3):221-230. doi:10.1093/heapol/16.3.221

153. Haldane V, Chuah FLH, Srivastava A, et al. Community participation in health services development, implementation, and evaluation: a systematic review of empowerment, health, community, and process outcomes. PLoS One. 2019;14(5):e0216112. doi:10.1371/ journal.pone.0216112

154. Beier JC, Keating J, Githure JI, Macdonald MB, Impoinvil DE, Novak RJ. Integrated vector management for malaria control. Malar J. 2008;7(Supp11):S4. doi:10.1186/1475-2875-7-S1-S4

155. Chen WI. Malaria eradication in Taiwan, 1952-1964-some memorable facts. Gaoxiong Yi Xue Ke Xue Za Zhi. 1991;7:263-270.

156. Espino F, Koops V, Manderson L. Community Participation and Tropical Disease Control in Resource-Poor Settings. Social, Economic, and Behavioral Research Special Topics Geneva. Special Programme for Research \& Training in Tropical Diseases (TDR); 2004:1-48.

157. Henderson RH. Eradication: lessons from the past. Bull World Health Organ. 1998;76:17-21.

158. Kaneko A, Taleo G, Kalkoa M, Yamar S, Kobayakawa T, Bjorkman A. Malaria eradication on islands. Lancet. 2000;356:1560-1564. doi:10.1016/S0140-6736(00)03127-5

159. Pribadi W, Muzaham F, Santoso T, Rasidi R, Rukmono B. Soeharto: the implementation of community participation in the control of malaria in rural Tanjung Pinang, Indonesia. Southeast Asian J Trop Med Public Health. 1986;17:371-378.

160. Sleigh A, Xueming L, Jackson S, Huang K. Eradication of schistosomiasis in Guangxi, China. Part 1: setting, strategies, operations, and outcomes, 1953-92. Bull World Health Organ. 1998;76:361-372.

161. Narain JP. Integrating services for noncommunicable diseases prevention and control: use of primary health care approach. Indian $J$ Community Med. 2011;36(Suppl 1):S67-S71. doi:10.4103/09700218.94712

162. Rule J, Ngo DA, Oanh TT, et al. Strengthening primary health care in low- and middle-income countries: generating evidence through evaluation. Asia Pac J Public Health. 2014;26(4):339-348. doi:10.1177/1010539513503869

163. Piot P, Caldwell A, Lamptey $\mathrm{P}$, et al. Addressing the growing burden of non-communicable disease by leveraging lessons from infectious disease management. $J$ Glob Health. 2016;6(1):010304. doi:10.7189/jogh.06.010304

164. Allotey P, Davey T, Reidpath DD. NCDs in low and middleincome countries - assessing the capacity of health systems to respond to population need. BMC Public Health. 2014;14 Suppl 2 (Supp12):S1. doi:10.1186/1471-2458-14-S2-S1

165. Guinness L, Wiseman V. Understanding Public Health. Introduction to Health Economics. 2nd. Shoppenhangers Road, Maidenhead, Berkshire, England, SL6 2QL, UK: Open University Press, McGraw-Hill Education, McGraw-Hill House; 2011. Available from: https://docuri.com/queue/lorna-guinness-virginiawiseman-david-wonderlinbookzzorg_59bf38b4f581716e46c36f4e pdf?queue_id=59fa054ff58171c34d792ff3. Accessed June 20, 2019

166. Wyatt R, Laderman M, Botwinick L, Mate K, Whittington J Achieving health equity: a guide for health care organizations. IHI white paper. Cambridge, MA: Institute for Healthcare Improvement; 2016. Available from: www.ihi.org/resources/ Pages/IHIWhitePapers/Achieving-Health-Equity.aspx. Accessed June 21, 2019. 
167. The Picket Line. Aristotle on Distributive Justice. Available from: https://sniggle.net/TPL/index5.php?entry=140ct09. Accessed June 20, 2019.

168. Ross WD. Aristotle Nicomachean Ethics (Translated). Kitchener: Batoche Books; 1999. Available from: https://socialsciences. mcmaster.ca/econ/ugcm/3113/aristotle/Ethics.pdf. Accessed June 20, 2019

169. Knoll M. The Meaning of Distributive Justice for Aristotle's Theory of Constitutions. Istanbul Şehir University; 2016; doi:10.20318/ fons.2016.2529

170. Health Knowledge. Equity in health care. Public Health Action Support Team (PHAST); 2017. Available https://www.healthknow ledge.org.uk/public-health-textbook/research-methods/1c-healthcare-evaluation-health-care-assessment/equity-health-care. Accessed June 20, 2019.

171. Zere E, Moeti M, Kirigia J, Mwase T, Kataika E. Equity in health and healthcare in Malawi: analysis of trends. BMC Public Health. 2007;7:78. doi:10.1186/1471-2458-7-78

172. Andermann A; CLEAR Collaboration. Acting on the social determinants of health in clinical practice: a framework for health professionals. CMAJ. 2016;188(17-18):E474-E483. doi:10.1503/ cmaj. 160177

173. Islam SM, Purnat TD, Phuong NT, Mwingira U, Schacht K, Fröschl G. Non-communicable diseases (NCDs) in developing countries: a symposium report. Global Health. 2014;10:81. doi:10.1186/s12992-014-0081-9

174. Checkley W, Ghannem H, Irazola V, et al.; GRAND South Network, UnitedHealth Group/National Heart, Lung, and Blood Institute Centers of Excellence. Management of NCD in low- and middle-income countries. Glob Heart. 2014;9(4):431-443. doi:10. 1016/j.gheart.2014.11.003.

175. World Health Organization. Access to non-communicable disease medicines. Essential medicines and health products. Available from: https://www.who.int/medicines/areas/policy/access_noncom municable/en/.Accessed June 18, 2019.

176. Shield KD, Parry C, Rehm J. Chronic diseases and conditions related to alcohol use. Alcohol Res. 2014;35(2):155-173.

177. Richard L, Furler J, Densley K, et al. Equity of access to primary healthcare for vulnerable populations: the IMPACT international online survey of innovations. Int $J$ Equity Health. 2016;15:64. doi:10.1186/s12939-016-0351-7

178. Lunenfeld B, Stratton P. The clinical consequences of an ageing world and preventive strategies. Best Pract Res Clin Obstet Gynaecol. 2013;27(5):643-659. doi:10.1016/j.bpobgyn.2013.02. 005

179. McManus A. Health promotion innovation in primary health care. Australas Med J. 2013;6(1):15-18. doi:10.4066/AMJ.2013.1578

180. Lund S, Probst HB, Bygbjerg IC. Can strategy for primary health care be revitalized 30 years after Alma-Ata? Ugeskr Laeger. 2010;172(49):3414-3417.

181. Yuasa M, Suganami S, Nakahara T. Similarity between primary health care and health promotion. Nihon Koshu Eisei Zasshi. 2001;48(7):513-520.

182. Son HH Equity and Well-Being. Measurement and policy practice. Routledge 2 Park Square, Milton Park, Abingdon, Oxon OX14 4RN; 2011. Available from: https://www.adb.org/sites/default/ files/publication/29288/equity-well-being.pdf. Accessed June 20, 2019.

183. Balarajan Y, Selvaraj S, Subramanian SV. Health care and equity in India. Lancet. 2011;377(9764):505-515. doi:10.1016/S0140-6736 (10)61894-6

184. López-Casasnovas G, Soley-Bori M. The socioeconomic determinants of health: economic growth and health in the OECD countries during the last three decades. Int $J$ Environ Res Public Health. 2014;11(1):815-829. doi:10.3390/ijerph11010 0815
185. Macinko J, Starfield B, Erinosho T. The impact of primary healthcare on population health in low- and middle-income countries. $J$ Ambul Care Manage. 2009;32(2):150-171. doi:10.1097/JAC.0b01 3e3181994221

186. Asante A, Price J, Hayen A, Jan S, Wiseman V. Equity in health care financing in low- and middle-income countries: a systematic review of evidence from studies using benefit and financing incidence analyses. PLoS One. 2016;11(4):e0152866. doi:10.1371/ journal.pone. 0152866

187. Anderson GF, Waters H, Pittman P, Herbert R, Chu E, Das K NonCommunicable Chronic Diseases in Latin America and the Caribbean. Bloomberg School of Public Health, Johns Hopkins University, Baltimore, Maryland, USA. LAC Bureau of the U.S. Agency for International Development; 2009. Available from: http://www.healthycaribbean.org/publications/documents/NCD-inLAC-USAID.pdf. Accessed June 8, 2019.

188. Pan American Health Organization. Proposed strategic plan 2008-2012. Situation analysis in the region. Economic and social trends. Available from: http://amro.who.int/English/GOV/CSP/ od328-analysis-e.pdf. Accessed June 8, 2019.

189. Mayo Clinic Staff. High blood pressure (hypertension); 2018. Available from: https://www.mayoclinic.org/diseases-conditions/ high-blood-pressure/symptoms-causes/syc-20373410. Accessed June 8, 2019.

190. World Health Organization. Noncommunicable diseases. Management of noncommunicable diseases in primary health care; 2019 Available from: http://www.emro.who.int/noncommunic able-diseases/publications/questions-and-answers-on-managementof-noncommunicable-diseases-in-primary-health-care.html. Accessed June 8, 2019.

191. Manjomo RC, Mwagomba B, Ade S, et al. Managing and monitoring chronic non-communicable diseases in a primary health care clinic, Lilongwe, Malawi. Public Health Action. 2016;6(2):60-65. doi:10.5588/pha.16.0003

192. Saleh S, Farah A, El Arnaout N, et al. mHealth use for noncommunicable diseases care in primary health: patients' perspective from rural settings and refugee camps. J Public Health (Oxf). 2018;40(suppl 2):ii52-ii63. doi:10.1093/pubmed/fdy172

193. Khader A, Farajallah L, Shahin Y, et al. Cohort monitoring of persons with hypertension: an illustrated example from a primary healthcare clinic for Palestine refugees in Jordan. Trop Med Int Health. 2012;17 (9):1163-1170. doi:10.1111/j.1365-3156.2012.03048

194. Khader A, Farajallah L, Shahin Y, et al. Hypertension and treatment outcomes in Palestine refugees in United Nations Relief and Works Agency primary health care clinics in Jordan. Trop Med Int Health. 2014;19(10):1276-1283. doi:10.1111/tmi.12356

195. Khader A, Ballout G, Shahin Y, et al. Treatment outcomes in a cohort of Palestine refugees with diabetes mellitus followed through use of E-Health over three years in Jordan. Trop Med Int Health. 2014;19(2):219-223. doi:10.1111/tmi.12241

196. Murray CJ, Vos T, Lozano R, et al. Disability-adjusted life years (DALYs) for 291 diseases and injuries in 21 regions, 1990-2010: a systematic analysis for the Global Burden of Disease Study 2010. Lancet. 2012;380(9859):2197-2223. doi:10.1016/S0140-6736(12) 61689-4

197. Raghupathi W, Raghupathi V. An empirical study of chronic diseases in the United States: a visual analytics approach. Int $J$ Environ Res Public Health. 2018;15(3):431. doi:10.3390/ijerph 15030431

198. Ajay VS, Watkins DA, Prabhakaran D. Relationships among major risk factors and the burden of cardiovascular diseases, diabetes, and chronic lung disease. In: Prabhakaran D, Anand S, Gaziano TA, et al. editors. Cardiovascular, Respiratory, and Related Disorders. 3rd. Washington (DC): The International Bank for Reconstruction and Development/The World Bank; 2017. doi:10.1596/978-1-4648$0518-9 / \operatorname{ch} 2$ 
199. Kroll M, Phalkey RK, Kraas F. Challenges to the surveillance of non-communicable diseases-a review of selected approaches. BMC Public Health. 2015;15:1243. doi:10.1186/s12889-015-2570-z

200. Megari K. Quality of life in chronic disease patients. Health Psychol Res. 2013;1(3):e27. doi:10.4081/hpr.2013.e27

201. Committee on Diagnostic Error in Health Care; Board on Health Care Services; Institute of Medicine; The National Academies of Sciences, Engineering, and Medicine; Balogh EP, Miller BT, Ball $\mathrm{JR}$, editors. Improving Diagnosis in Health Care. Washington (DC): National Academies Press (US); 2015:2. The Diagnostic Process. Available from: https://www.ncbi.nlm.nih.gov/books/ NBK338593/. Accessed February 11, 2020

202. World Health Organization. Primary health care; 2019. Available from: https://www.who.int/news-room/fact-sheets/detail/primaryhealth-care. Accessed February 11, 2020.

203. Du S, Cao Y, Zhou T, et al. The knowledge, ability, and skills of primary health care providers in SEANERN countries: a multinational cross-sectional study. BMC Health Serv Res. 2019;19 (1):602. doi:10.1186/s12913-019-4402-9

204. Grover A, Joshi A. An overview of chronic disease models: a systematic literature review. Glob J Health Sci. 2014;7(2):210227. doi: $10.5539 /$ gjhs.v7n2p210

205. Huh J, Ackerman MS. Collaborative help in chronic disease management: supporting individualized problems. CSCW Conf Comput Support Coop Work. 2012;2012:853-862. doi:10.1145/2145204. 2145331

206. Thomas SL, Wakerman J, Humphreys JS. Ensuring equity of access to primary health care in rural and remote Australia - what core services should be locally available? Int J Equity Health. 2015;14:111. doi:10.1186/s12939-015-0228-1n

207. Okpokoro E. Primary health care: a necessity in developing countries? J Public Health Afr. 2013;4(2):e17. doi:10.4081/jphia.2013. e17

208. National Research Council (US); Institute of Medicine (US); Woolf $\mathrm{SH}$, Aron L, editors. U.S. Health in International Perspective: Shorter Lives, Poorer Health. Washington (DC): National Academies Press (US); 2013:4. Public Health, and Medical Care Systems. Available from: https://www.ncbi.nlm.nih.gov/books/ NBK154484/. Accessed February 11, 2020

209. Weatherall D, Greenwood B, Chee HL, et al. Science and technology for disease control: past, present, and future. In: Jamison DT, Breman JG, Measham AR, et al. editors. Disease Control Priorities in Developing Countries. 2nd. Washington (DC): The International Bank for Reconstruction and Development/The World Bank; 2006. Chapter 5. Available from: https://www.ncbi.nlm.nih.gov/books/ NBK11740/. Co-published by Oxford University Press, New York. Accessed February 11, 2020.

210. Hussein J. Non-communicable diseases during pregnancy in low and middle-income countries. Obstet Med. 2017;10(1):26-29. doi:10.1177/1753495X16684709

211. Gülmezoglu AM, Lawrie TA, Hezelgrave N, et al. Interventions to Reduce Maternal and Newborn Morbidity and Mortality. In: Black RE, Laxminarayan R, Temmerman M, et al. editors. Reproductive, Maternal, Newborn, and Child Health: Disease Control Priorities. Third. Vol. 2. Washington (DC): The International Bank for Reconstruction and Development/The World Bank; 2016. doi:10.1596/978-1-4648-0348-2 ch7

212. Institute of Medicine (US) Committee on Employment-Based Health Benefits; Field MJ, Shapiro HT, editors. Employment and Health Benefits: A Connection at Risk. Washington (DC): National Academies Press (US); 1993:6. Health Care Costs: More Questions than Answers. Available from: https://www.ncbi.nlm.nih.gov/ books/NBK235994/. Accessed February 11, 2020

213. Aregbeshola BS, Khan SM. Primary Health Care in Nigeria: 24 Years after Olikoye Ransome-Kuti's Leadership. Front Public Health. 2017;5:48. doi:10.3389/fpubh.2017.00048
214. Basu S, Andrews J, Kishore S, Panjabi R, Stuckler D. Comparative performance of private and public healthcare systems in low- and middle-income countries: a systematic review. PLoS Med. 2012;9 (6):e1001244. doi:10.1371/journal.pmed.1001244

215. Berendes S, Heywood P, Oliver S, Garner P. Quality of private and public ambulatory health care in low and middle-income countries: systematic review of comparative studies. PLoS Med. 2011;8(4): e1000433. doi:10.1371/journal.pmed.1000433

216. National Research Council (US) Committee on Population; Gribble JN, Preston SH, editors. The epidemiological transition: policy and planning implications for developing countries: Workshop Proceedings. Washington (DC): National Academies Press (US); 1993. Health, Government, and the Poor: the Case for the Private Sector. Available from: https:/www.ncbi.nlm.nih.gov/books/ NBK236443/. Accessed April 14, 2020.

217. Angell M. Privatizing health care is not the answer: lessons from the United States. CMAJ. 2008;179(9):916-919. doi:10.1503/ cmaj.081177

218. McKee M, Stuckler D. The crisis of capitalism and the marketization of health care: the implications for public health professionals. J Public Health Res. 2012;1(3):236-239. doi:10.4081/ jphr.2012.e37

219. Obama B. United States Health Care Reform: progress to Date and Next Steps. JAMA. 2016;316(5):525-532. doi:10.1001/jama.2016. 9797

220. Tran LD, Zimmerman FJ, Fielding JE. Public health and the economy could be served by reallocating medical expenditures to social programs. SSM Popul Health. 2017;3:185-191. doi:10.1016/j. ssmph.2017.01.004

221. Schieber G, Baeza C, Kress D, et al. Financing Health Systems in the 21 st Century. In: Jamison DT, Breman JG, Measham AR, et al. editors. Disease Control Priorities in Developing Countries. 2nd. Washington (DC): The International Bank for Reconstruction and Development/The World Bank; 2006. Chapter 12. Available from: https://www.ncbi.nlm.nih.gov/books/NBK11772/. Co-published by Oxford University Press, New York. Accessed February 11, 2020.

222. Kruk ME, Nigenda G, Knaul FM. Redesigning primary care to tackle the global epidemic of noncommunicable disease. Am J Public Health. 2015;105(3):431-437. doi:10.2105/AJPH.2014. 302392

223. Sinha R, Pati S. Addressing the escalating burden of chronic diseases in India: need for strengthening primary care. J Family Med Prim Care. 2017;6(4):701-708. doi:10.4103/jfmpc.jfmpc_1_17

224. Hall JJ, Taylor R. Health for all beyond 2000: the demise of the Alma-Ata Declaration and primary health care in developing countries. Med J Aust. 2003;178(1):17-20. doi:10.5694/j.1326-5377. 2003.tb05033.x

225. Morgan R, Ensor T, Waters H. Performance of private-sector health care: implications for universal health coverage. Lancet. 2016;388 (10044):606-612. doi:10.1016/S0140-6736(16)00343-3

226. Robinson HM, Hort K. Non-communicable diseases and health systems reform in low-and-middle-income countries. Pac Health Dialog. 2012;18(1):179-190.

227. Sheikhattari P, Kamangar F. How can primary health care system and community-based participatory research be complementary? Int J Prev Med. 2010;1(1):1-10.

228. MacCormack CP. Community participation in primary health care. Trop Doct. 1983;13(2):51-54. doi:10.1177/004947558301300202

229. Walraven G. The 2018 Astana Declaration on Primary Health Care, is it useful? J Glob Health. 2019;9(1):010313. doi:10.7189/ jogh.09.010313

230. Abimbola S, Negin J, Jan S, Martiniuk A. Towards people-centered health systems: a multi-level framework for analyzing primary health care governance in low- and middle-income countries. Health Policy Plan. 2014;29 Suppl 2(Supp12):ii29-ii39. doi:10.10 93/heapol/czu069 
231. Department of Health. The Republic of South Africa. Strategic Plan for The Prevention and Control of Non-Communicable Diseases 2013-17. Available from: https:/extranet.who.int/ncdccs/ Data/ZAF_B3_NCDs_STRAT_PLAN_1_29_1_3\%5B2\%5D.pdf. Accessed February 11, 2020.

232. Kumar S, Preetha G. Health promotion: an effective tool for global health. Indian J Community Med. 2012;37(1):5-12. doi:10.4103/ 0970-0218.94009

233. Boyce T, Peckham S, Hann A, Trenholm S A pro-active approach. Health Promotion and Ill-health prevention. The Kings Fund; 2010. Available from: https://www.kingsfund.org.uk/sites/ default/files/field/field_document/health-promotion-ill-health-pre vention-gp-inquiry-research-paper-mar11.pdf. Accessed February $11,2020$.

234. Srivastava RK, Bachani D. Burden of NCDs, Policies, and Programme for Prevention and Control of NCDs in India. Indian J Community Med. 2011;36(Suppl 1):S7-S12. doi:10.4103/09700218.94703
235. Ramli A, Taher S. Managing chronic diseases in the Malaysian primary health care - a need for change. Malays Fam Physician. 2008;3(1):7-13.

236. Ramli AS, Lakshmanan S, Haniff J, et al. Study protocol of EMPOWER participatory action research (EMPOWER-PAR): a pragmatic cluster randomized controlled trial of multifaceted chronic disease management strategies to improve diabetes and hypertension outcomes in primary care. BMC Fam Pract. 2014;15:151. doi:10.1186/1471-2296-15-151

237. Bachmann MO, Bateman ED, Stelmach R, et al. Integrating primary care of chronic respiratory disease, cardiovascular disease, and diabetes in Brazil: practical Approach to Care Kit (PACK Brazil): study protocol for randomized controlled trials. J Thorac Dis. 2018;10(7):4667-4677. doi:10.21037/jtd.2018.07.34

238. Ramli AS, Selvarajah S, Daud MH, et al. Effectiveness of the EMPOWER-PAR intervention in improving clinical outcomes of type 2 diabetes mellitus in primary care: a pragmatic cluster randomised controlled trial. BMC Fam Pract. 2016;17(1):157. doi:10.1186/ s12875-016-0557-1
Risk Management and Healthcare Policy

\section{Publish your work in this journal}

Risk Management and Healthcare Policy is an international, peerreviewed, open access journal focusing on all aspects of public health, policy, and preventative measures to promote good health and improve morbidity and mortality in the population. The journal welcomes submitted papers covering original research, basic science, clinical \& epidemiological studies, reviews and evaluations,

\section{Dovepress}

guidelines, expert opinion and commentary, case reports and extended reports. The manuscript management system is completely online and includes a very quick and fair peer-review system, which is all easy to use. Visit http://www.dovepress.com/testimonials.php to read real quotes from published authors. 